\title{
Absorção de Molibdênio pela Cana de Açúcar Variedade Co 419, em função da idade
}

N. A. DA GLóRIA, R. A. CATANI, H. BERGAMIN FILHO

D. PELLEGRINO

(*) Trabalho executado com auxílio fornecido pela Fundação de Amparo à Pesquisa do Estado de São Paulo. 


\section{1 - INTRODUÇÃO}

A importância do molibdênio na nutrição das plantas tem sido salientada por diversos autores, assim como os fatôres que influenciam sua disponibilidade no solo (EVANS, 1956; DAVIES, 1956).

Entretanto, o maior volume de trabalhos publicados, com referência ao citado micronutriente, tem sido dedicado às plantas hortícolas (STOUT \& JOHNSON, 1956; HEWITT, 1956).

EVANS (1955), determinou a quantidade de molibdênio encontrada na cana de açúcar, nos diferentes estágios de seu desenvolvimento. Este mesmo autor, relata prováveis sintomas de deficiência de molibdênio em cana de açúcar crescente em condições de campo.

A concentração de molibdênio em cana de açúcar varia conforme a região, assim como são também variáveis os teores encontrados nas diferentes partes da planta, conforme cita EVANS (1959).

O conhecimento da quantidade de nutrientes absorvidos pelas plantas, durante seu ciclo evolutivo, permite obter-se uma idéia das exigências dêsses elementos nos diversos estágios do desenvolvimento das culturas.

Para a cana de açúcar variedade Co 419 , crescendo em condições de campo, na região de Piracicaba, Estado de São Paulo, já foram obtidos dados referentes a vários nutrientes (CATANI et al, 1959).

Em continuação ao trabalho acima mencionado, tem sido publicados ou estão para ser divulgado, dados referentes a.alguns micronutrientes como manganês (PELLEGRINO et al, 1962) zinco (PELLEGRINO et al, 1962) e ferro (BITTENCOURT et al, 1963) .

O objetivo do presente trabalho é determinar a concentração de molibdênio do côlmo e fôlha da cana de açúcar, assim como a quantidade do citado elemento absorvido pela planta, durante os diferentes estágios do seu desenvolvimento. 


\section{2 - MATERIAL E MÉTODO}

O material constou de 4 touceiras de cana, variedade Co 419 , colhidas mensalmente de um experimento com 6 canteiros, sendo 3 sém adubo e 3 adubados com $40 \mathrm{Kg}$. de $\mathrm{N}$ (sulfato de amônio), $100 \mathrm{Kg}$. de $\mathrm{P}_{2} \mathrm{O}_{5}$ (superfosfato simples) e $40 \mathrm{Kg}$. de $\mathrm{K}_{20} 0$ (cloreto de potássio) por hectare, na época do plantio. O experimento foi instalado na Estação Experimental de Cana "Dr. José Vizioli", Piracicaba, Estado de São Paulo.

Colheram-se as partes aéreas de 4 touceiras de cada tratamento e pesaram-se. Separaram-se as pontas de côlmo e pesaram-se separadamente. Das partes, retiraram-se amostras representativas que foram preparadas para as determinações. Os pêsos obtidos e as curvas de crescimento em função da idade já foram descritos em trabalho anterior (CATANI et al, 1959).

O método de análise empregado, baseia-se no uso de uma mistura de solventes de densidade superior a um, já preconizada por JOHNSON \& ARKLEY (1954) e modificada por GLÓRIA (1962), para a extração dos compostos coloridos formadós pela reação do molibdênio com o ânion tiocinato em presença do cloreto estanoso.

As leituras foram feitas em espectrofotômetro Beckman, Modêlo B.

\section{Reagentes:}

Solução de tiocianato de potássio a $30 \%$ : 30 g. de KCNS p.a. em $100 \mathrm{ml}$. de solução.

Solução de cloreto estanoso a $40 \%$ : $40 \mathrm{~g}$. de $\mathrm{SnC1}_{2} \cdot 2 \mathrm{H}_{2} \mathrm{O}$ p.a. em $100 \mathrm{ml}$. de solução.

Solução extratora: constituída por partes iguais em volume de álcool isobutílico e tetracloreto de carbono.

Ácido clorídrico $6 \mathrm{~N}$ destilado: preparado pela destilação de nma solução de ácido clorídrico $(1+1)$.

Ácido clorídrico $6 \mathrm{~N}$ contendo $0,05 \%$ de $\mathrm{FeC1}_{3} .6 \mathrm{H}_{2} 0$ : 0,500 g. de $\mathrm{FeC}_{3} \cdot 6 \mathrm{H}_{2} 0 \mathrm{em} 1000 \mathrm{ml}$. de $\mathrm{HC} 16 \mathrm{~N}$ destilado.

Ácido clorídrico $2 \mathrm{~N}$ contendo $0,05 \%$ de $\mathrm{FeC1}_{3} .6 \mathrm{H}_{2} 0$ : $0,500 \mathrm{~g}$. de $\mathrm{FeC1}_{3}, 6 \mathrm{H}_{2} 0$ por $1000 \mathrm{ml}$. de $\mathrm{HC} 12 \mathrm{~N}$ destilado. 
Preparo das soluções padrões:

O preparo das soluções padrões foi feito a partir de uma solução de $\mathrm{Na}_{2} \mathrm{MoO}_{4} .2 \mathrm{H}_{2} \mathrm{O}$ p.a. na qual foi dosado o molibdênio, pelo método gravimétrico do molibdato de chumbo (SCOTT, 1939) .

A partir dessa solução foi preparada uma solução padrão "estoque" contendo 100 microgramas de molibdênio por ml e por diluição desta, uma série de soluções pađrões contendo, respectivamente, 0,$5 ; 1,0 ; 2,0 ; 4,0 ; 6,0 ; 8,0 ;$ e 10,0 microgramas de molibdênio por mililitro.

\section{Preparo das curvas paddrão}

Tomou-se $1 \mathrm{ml}$ de cada uma das soluções da série padrão já descrita, passou-se para funil de separação de $125 \mathrm{ml}$, contendo $10 \mathrm{ml}$ da solução de HC1 $6 \mathrm{~N}$ com $0,05 \%$ de $\mathrm{FeC1}_{3} .6 \mathrm{H}_{2} 0$. A seguir foi adicionado água desmineralizada até obter-se um volume de $45 \mathrm{ml}$, após o que adicionou-se $3 \mathrm{ml}$. da mistura de solventes (álcool isobutílico e tetracloreto de carbono) e os funís assim preparados foram agitados por 2 minutos. Completada a agitação, deixou-se descansar para a perfeita separação das fases após o que o excesso de solvente foi retirado.

Foi adicionado a seguir pela ordem, $1 \mathrm{ml}$ da solução de $\mathrm{KCNS}$ a $30 \%, 1 \mathrm{ml}$ da solução de $\mathrm{SnCl}_{2} \cdot 2 \mathrm{H}_{2} \mathrm{O}$ a $40 \%$ e $3 \mathrm{ml}$ da mistura de solventes observando-se o cuidado de agitar o funir vigorosamente após a adição de cada reativo. Procedeu-se a nova agitação por 2 minutos e após a separação das fases o solvente foi drenado para as cubetas do espectrofotômetro Beckman, Modêlo B, com comprimento de onda ajustado a $470 \mathrm{mu}$. A correlação entre densidade ótica e concentração das soluções padrões é linear dentro dos limites de trabalho.

\section{Determinação do molibdênio na cana}

Como a cana de açucar apresenta uma variação bastante sensível, na quantidade de molibdênio existente no côlmo e nas fôlhas, foi necessário empregar-se quantidades diversas de material para a análise, conforme se tratasse de côlmo ou fôlha a ser analisado, a fim de obter-se valores dignos de confiança, nas leituras no aparelho. 
A marcha analítica empregada foi a seguinte: pesou-se $10,00 \mathrm{~g}$ ou $5,000 \mathrm{~g}$ do material (conforme se tratasse de côlmo ou fôlha respectivamente), passou-se para cápsula de quartzo e a amostra foi incinerada por 2-3 horas à $500-550^{\circ}$ $\mathrm{C}$ após o que foi retomada com $10 \mathrm{ml}$ de $\mathrm{HCl} 2 \mathrm{~N}$ contendo $0,05 \%$ de $\mathrm{FeCl}_{3}$. $6 \mathrm{H}_{2} \mathrm{O}$, e aquecida até início de ebulição. O material foi filtrado e a cápsula e filtro foram lavados com $20 \mathrm{ml}$ de $\mathrm{HCl} 2 \mathrm{~N}$ em frações de $5 \mathrm{ml}$.

A solução assim obtida foi transferida para funil separador e procedeu-se conforme descrito no preparo da curva padrão.

Os valores das leituras foram comparados aos valores da curva padrão e calculados os microgramas de molibdênio. (Ver quadro 1).

Todos os cuidados com contaminação foram observados, assim como as demais preocupações inerentes ao método aplicado.

\section{3 - RESULTADOS OBTIDOS}

A concentração em ppm de molibdênio no côlmo e fôlhas da cana obtidas conforme já foi descrito pode ser observada no quadro 1.

\section{QUADRO 2}

Microgramas de molibdênio absorvido pelos colmos, fôlhas e plantas inteiras, de 4 touceiras nos dois tratamentos conforme a idade da planta

\begin{tabular}{|c|c|c|c|c|c|}
\hline \multirow{2}{*}{$\begin{array}{c}\text { Época } \\
\text { de } \\
\text { colheita }\end{array}$} & \multirow{2}{*}{$\begin{array}{l}\text { Idade da } \\
\text { planta em } \\
\text { meses }\end{array}$} & \multicolumn{2}{|c|}{ Sem adubo } & \multicolumn{2}{|c|}{ Com adubo } \\
\hline & & $\begin{array}{l}\text { côlmo } \\
\text { ppm Mo }\end{array}$ & $\begin{array}{l}\text { fôlha } \\
\text { ppm Mo }\end{array}$ & $\begin{array}{l}\text { côlmo } \\
\text { ppm Mo }\end{array}$ & $\begin{array}{l}\text { fôlha } \\
\text { ppm Mo }\end{array}$ \\
\hline Dezembro & 8 & 0,10 & 0,21 & 0,16 & 0,26 \\
\hline Janeiro & 9 & 0,42 & 0,41 & 0,45 & 0,31 \\
\hline Fevereiro & 10 & 0,22 & 0,25 & 0,21 & n.d. \\
\hline Marco & 11 & 0,10 & 0,33 & 0,29 & 0,30 \\
\hline Abril & 12 & 0,14 & 0,13 & 0,12 & 0,13 \\
\hline Maio & 13 & n.d. & 0,31 & 0,08 & 0,14 \\
\hline Junho & 14 & 0,05 & 0,50 & 0,06 & 0,89 \\
\hline
\end{tabular}




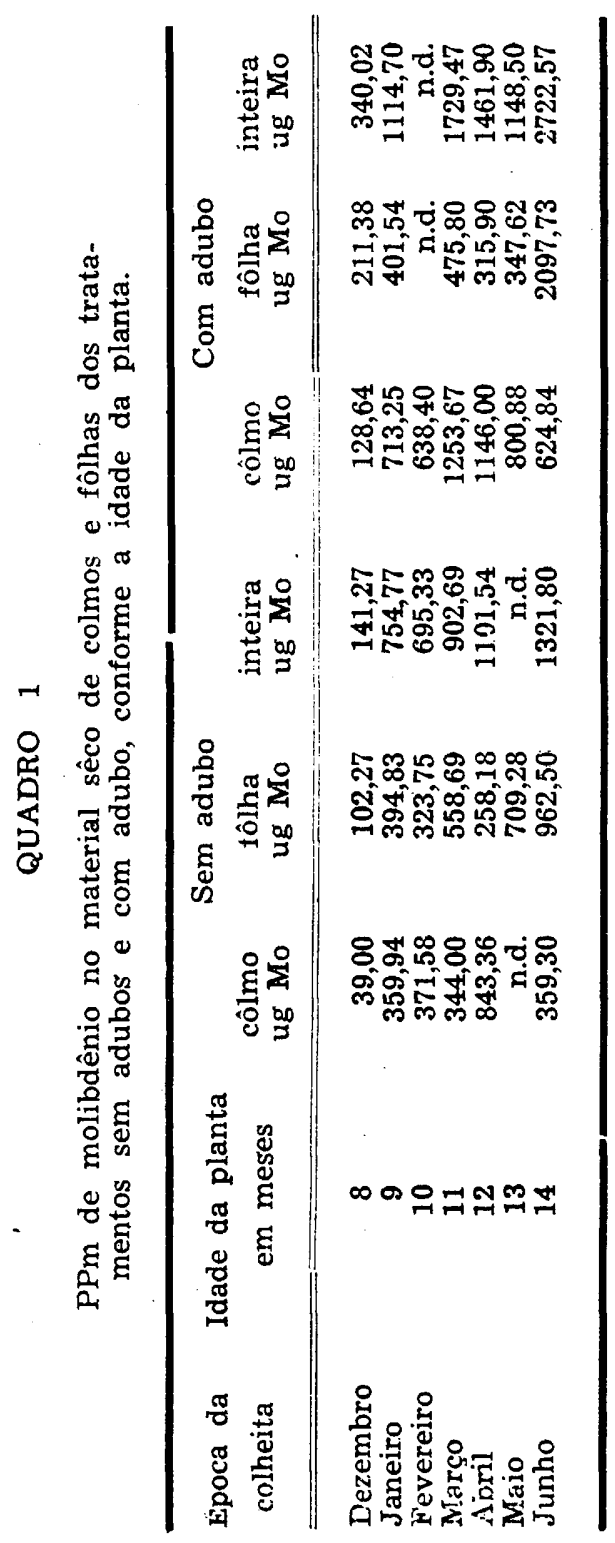




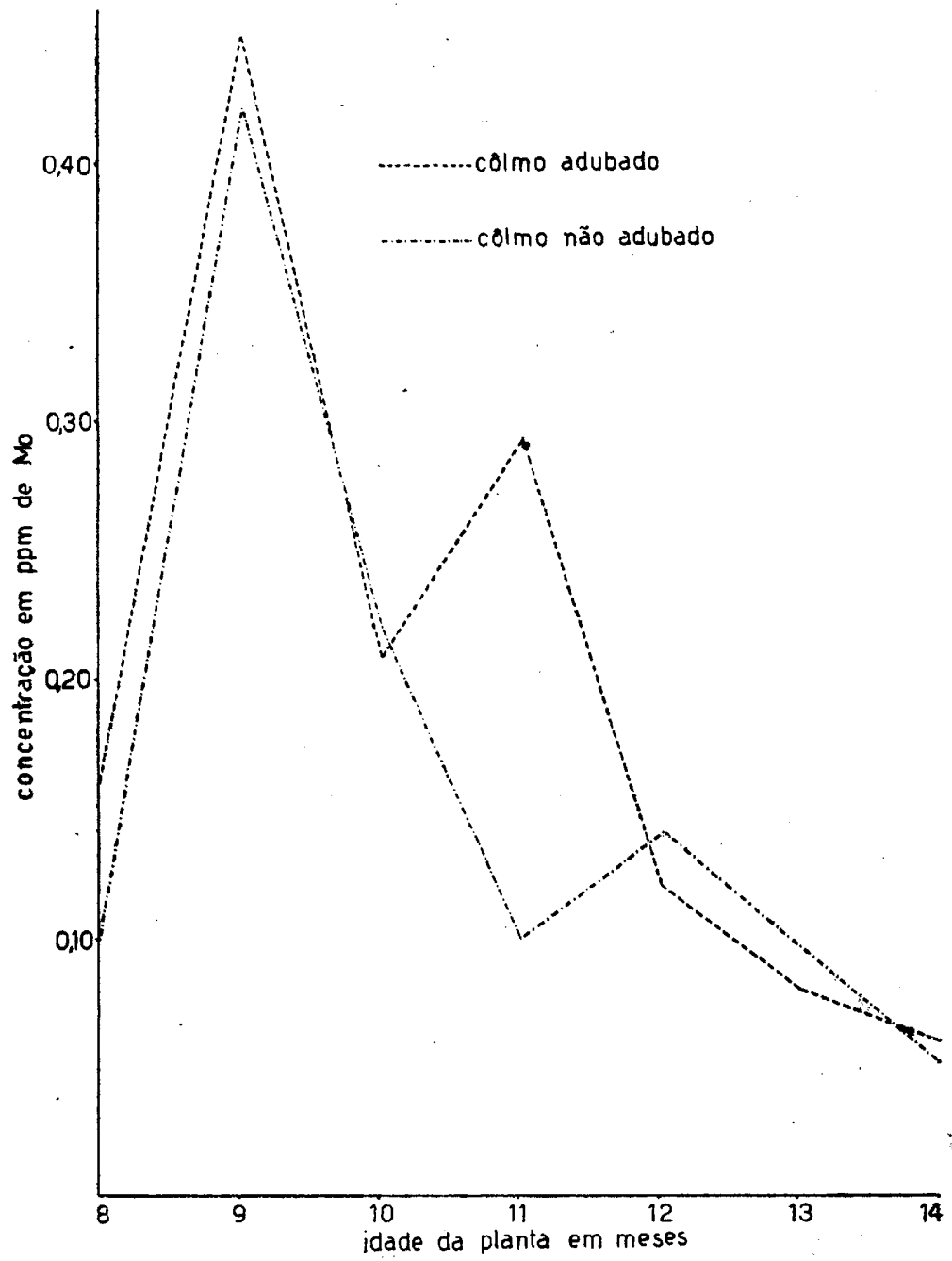

Fig. 1-Variaçăo do teor de Mo,em ppm, nos côlmos dos tratamentos adubado e não adubado, de acôrdo com a idade da planta, no material sêco. 


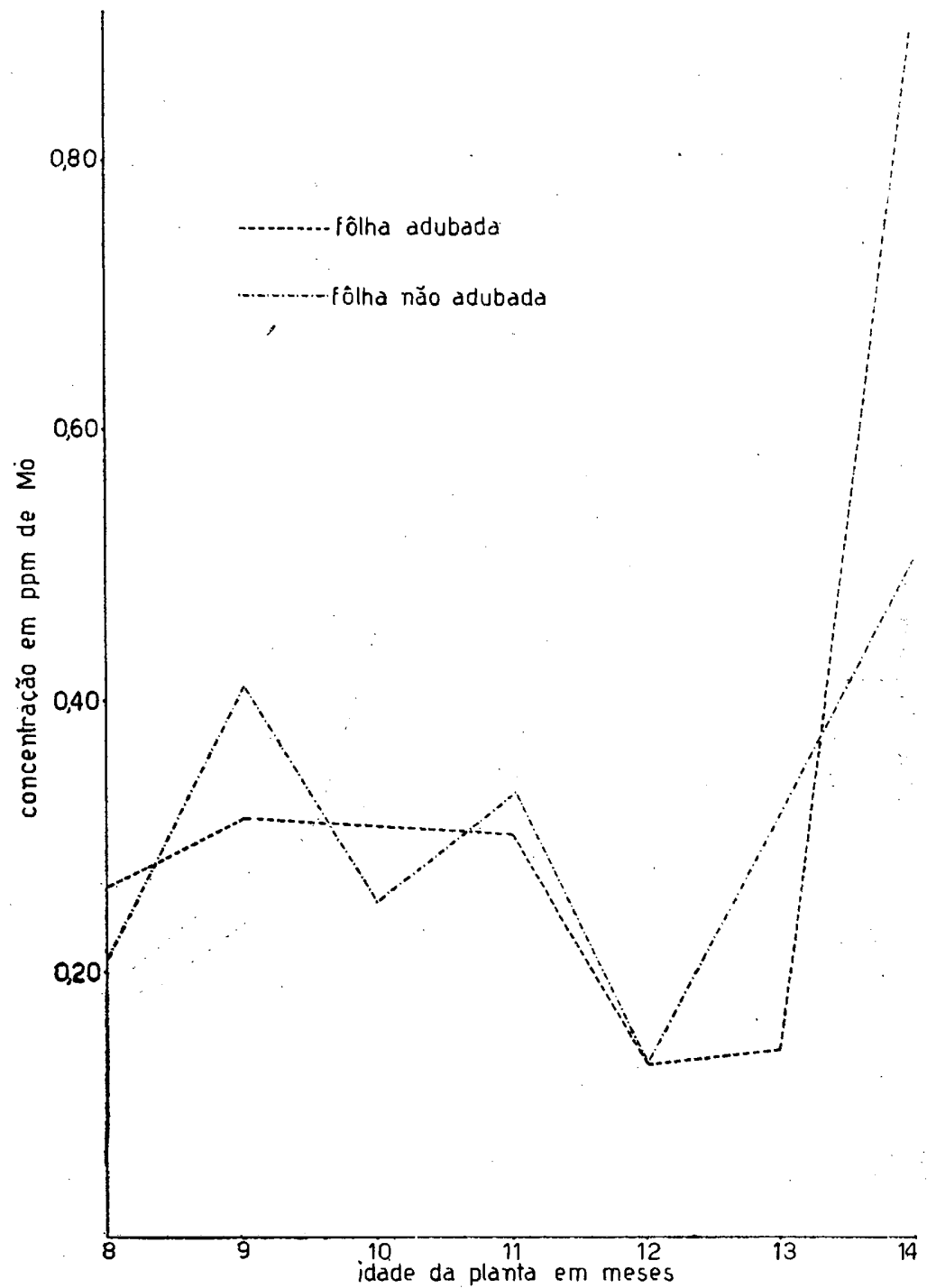

Fig.2-Variação do teor de Mo. em ppm, nas fôlhas dos tratamentos adubado e nao adubado, de acôrdo com a idade da planta, no material sêco 


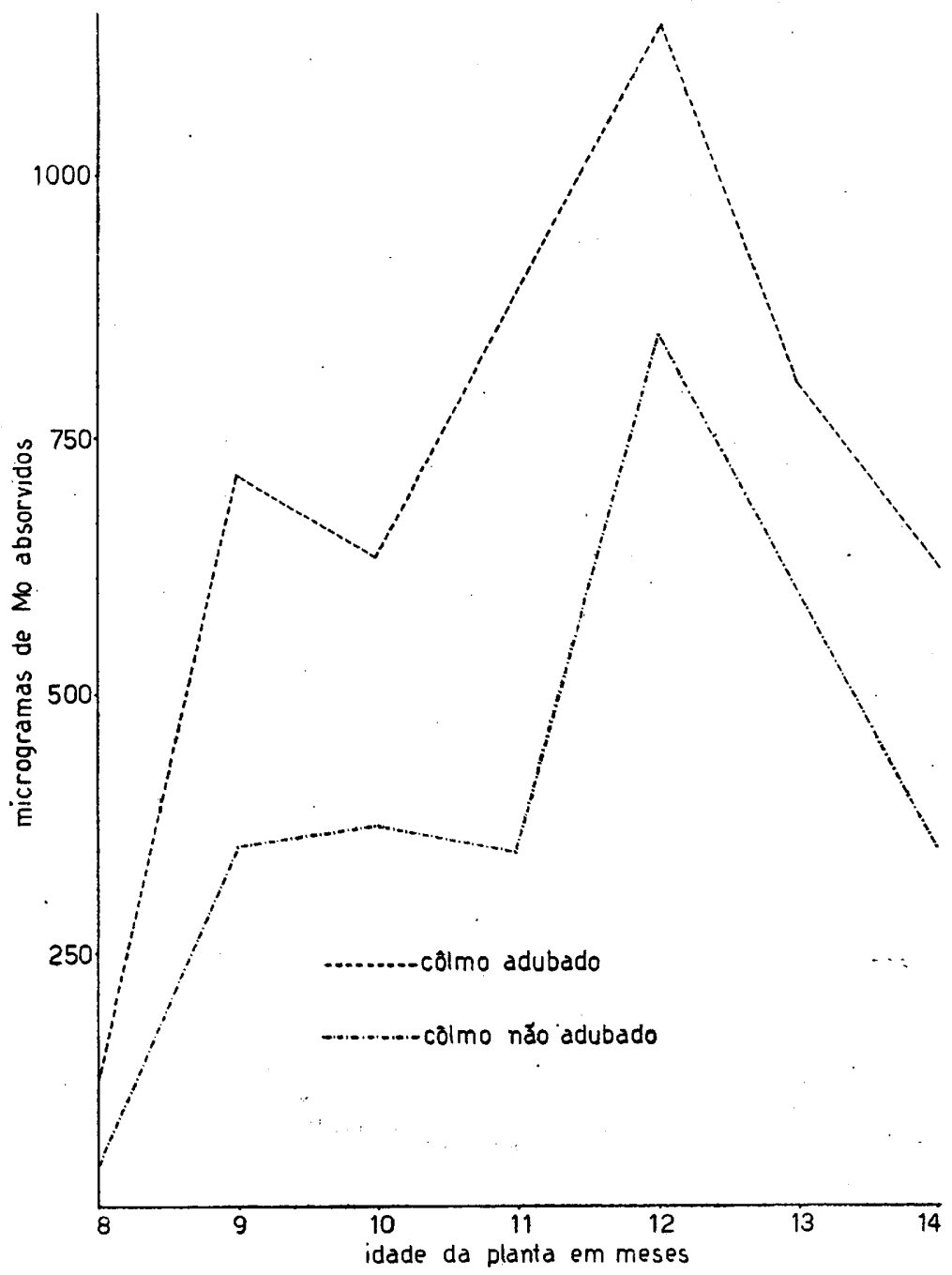

Fig. 3-Microgramas de Mo absorvidos pelos côlmos de 4 touceiras, dos tratamentos adubado e não adubado, de acôrdo com a idade da planta 


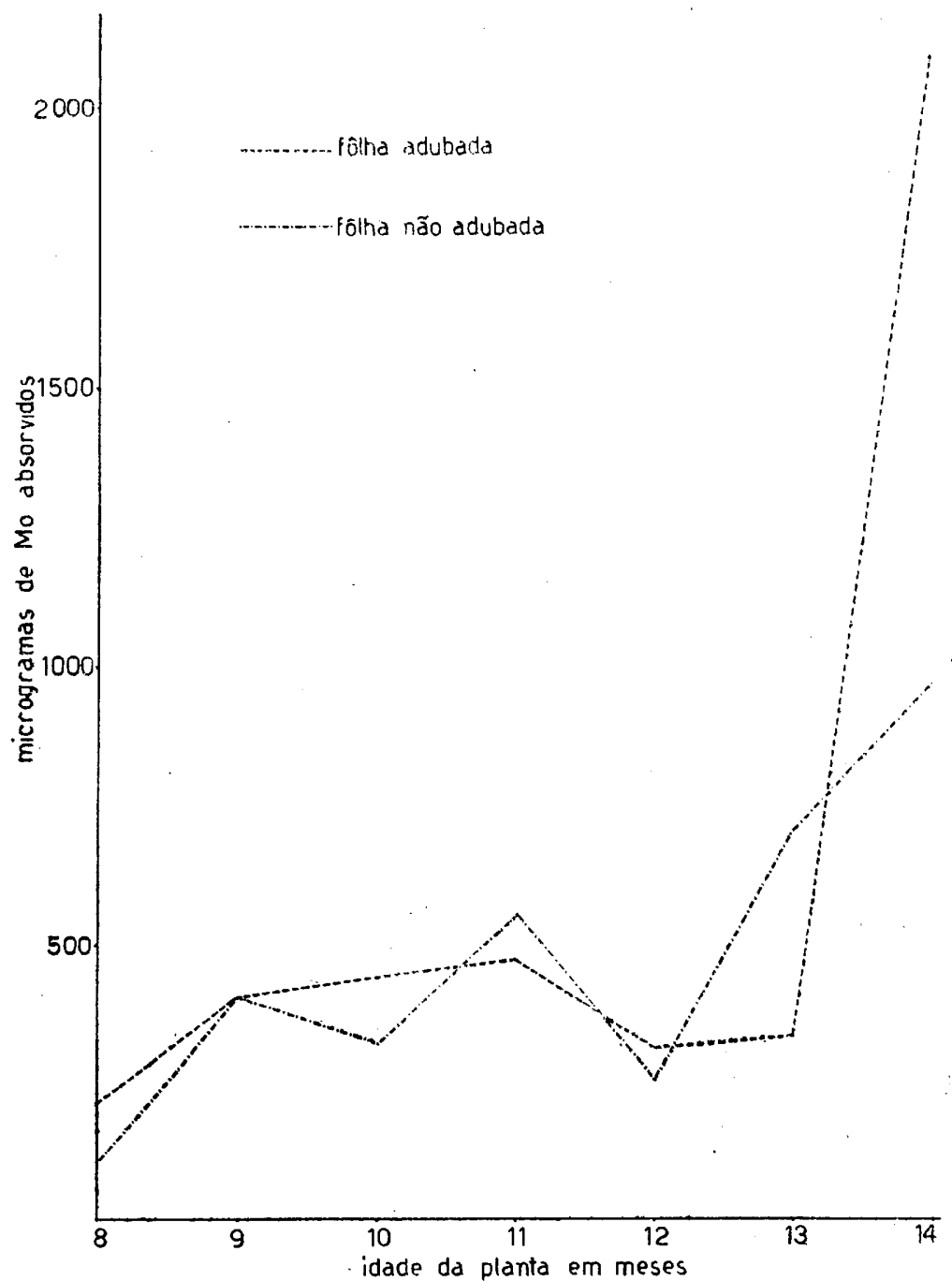

Fig. 4-Microgramas de Mo absorvidos pelas fôlhas de 4 touceiras, dos tratamentos adubado e não adubado, de acôrdo com a idade da planta. 


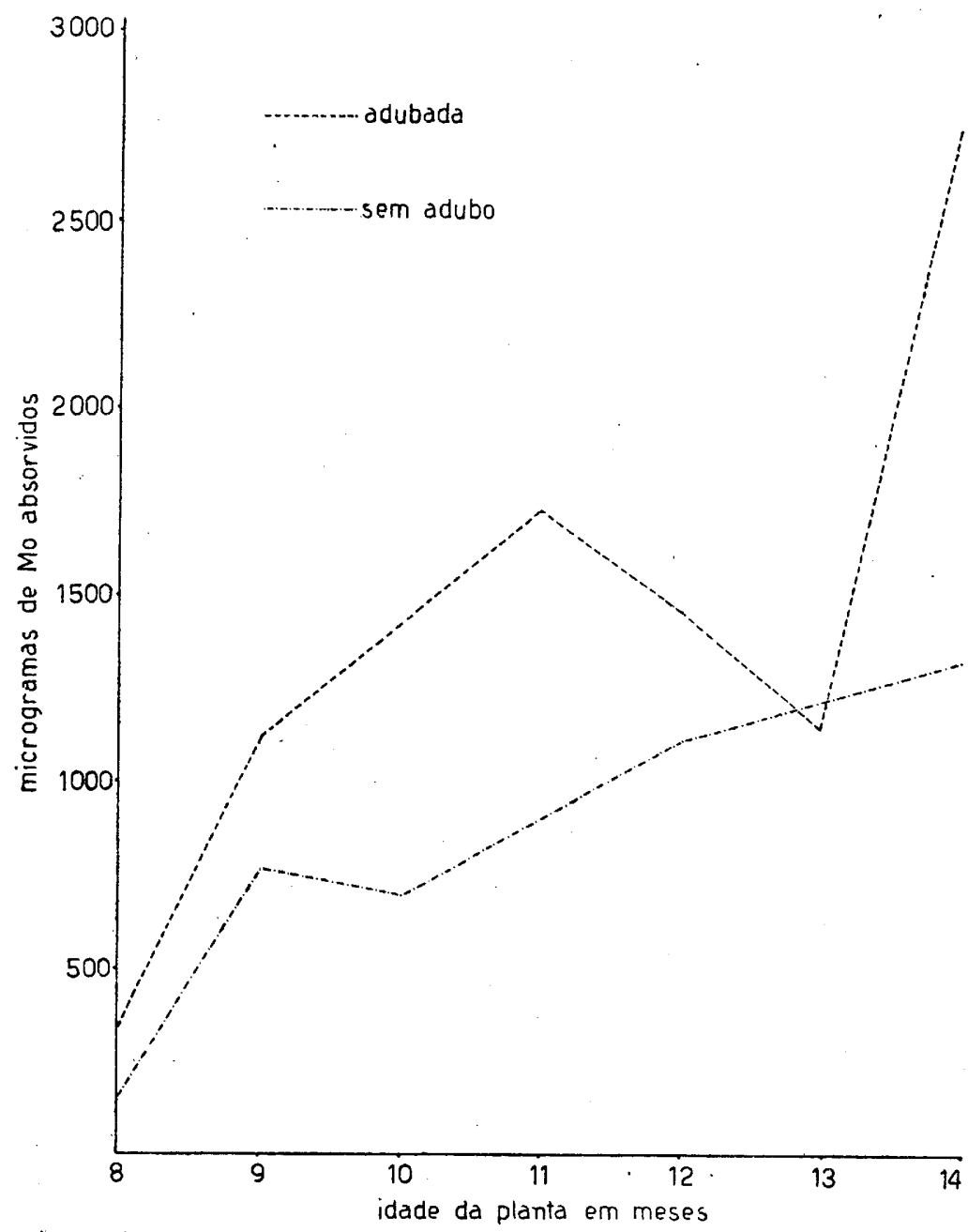

Fig.5-Microgramas de Mo absorvidos pelas plantas inteiras de 4 touceiras, dos tratamentos adubado e sem adubo, de acórdo com a idade da planta 
A quantidade em microgramas de molibdênio, absorvido pelas fôlhas, colmos e plantas inteiras de 4 touceiras, pode ser calculado pelos valores do quadro 1, quando relacionado com os pesos de material sêco, conforme CATANI et al (1959).

Os resultados dos quadros 1 e 2 permitem que se obtenha as curvas de absorção do molibdênio, pelo côlmo e fôlhas (fig. 1 e 2). Assim como, a absorção de molibdênio, pelo côlmo, fốlha e planta inteira das 4 touceiras, nos dois tratamentos (fig. 3,4 e 5 ).

\section{4 - RESUMO E CONCLUSÕES}

Êste trabalho relata os dados obtidos sôbre a determinação de molibdênio em diferentes partes da cana de açúcar, côlmo e fôlhas. As plantas analisadas, provinham de um experimento, no qual um dos tratamentos consistia de uma adubação com nitrogênio, fósforo e potássio e outro que não recebeu nenhuma adubação.

Após a determinação da concentração de molibdênio, foi possível calcular a quantidade dêste elemento absorvido pelas plantas inteiras de 4 touceiras.

Os resultados obtidos permitem as seguintes conclusões:

a) Houve uma grande variação na concentração de molibdênio, no côlmo da cana de açucar nos dois tratamentos, enquanto que para as fôlhas a variação foi menor, só aumentando no $14 .^{\circ}$ mês.

b) Há um certo paralelismo nas concéntrações de molibdênio tanto no côlmo como na fôlha, de ambos os tratamentos.

c) A concentração de molibdênio, no côlmo, declinou com o desenvolvimento da cana, como deveria ser esperado, dado o maior desenvolvimento dessa parte da planta.

d) No $14 .^{\circ}$ mês a quantidade de molibdênio no côlmo decresceu, talvez devido a migração do molibdênio para as fôlhas, cuja concentração aumentou muito.

e) A cana adubada absorveu maior quantidade de molibdênio, devido ao seu maior crescimento e portanto maior pêso de cana produzida. Houve, porém, um aumento quase 
contínuo, na absorção de molibdênio, pelas plantas dos dois tratamentos.

f) É grande a variação na quantidade de molibdênio absorvido pela cana de açúcar durante o seu desenvolvimento. Assim as fôlhas de um mesmo tratamento (adubado) apresentaram de 211,4 a 2097,7 microgramas, enquanto que no côlmo apresentaram de 128,6 a 1253,7 microgramas de molibdênio.

\section{5 - SUMMARY}

In this paper the authors describe the results obtained from the determination of molybdenum in sugar cane plant, grown in soils and climate prevailing in Piracicaba, State of São Paulo, Brazil.

The molybdenum was determined in samples cut monthly from the $8^{\text {th }}$ to $14^{\text {th }}$ month, from an experiment consisting of 6 plots, 3 fertilized and 3 unfertilized.

The fertilized treatment received $40 \mathrm{~kg} \mathrm{~N}$ (ammonium sulfate) $100 \mathrm{~kg} \mathrm{P} . \mathrm{O}_{\bar{y}}$ (superphosphate) and $40 \mathrm{~kg} \mathrm{~K}_{2} \mathrm{O}$ (potassium chloride) per hectare, just before planting.

Molybdenum was determined by thiocyanate-stannous chloride method, using carbon tetrachloride-butyl alcohol misture, for extrating the colored complex.

The results obtained show a parallelism in the absorption of molybdenum by the plants of both treatments.

The concentration of molybdenum in the stalks have a tendency to decrease, where as it kept more or less constant in leaves, with a exception in the $14^{3}$ month when it rised probable because of a migration of molybdenum of the stalks to the leaves.

The total amount molybdenum taken up was higher with the fertilized plot due its greater mass prodution. 


\section{6 - LITERATURA CITADA}

BITTENCOURT, V. C., R. A. CATANI, D. PELLEGRINO \& N. A. DA GLóRIA, 1963 - A absorção de ferro pela cana de açúcar, Co 419, em função da idade. No prelo dos Anais da E.S.A. "Luiz. de Queiroz", vol. 20-1963.

CATANI, R. A., H. C. ARRUDA, D. PELLEGRINO \& H. BERGAMIN FILHO - A absorção de nitrogênio, fósforo, potássio, cálcio, magnésio, enxôfre e silício pela cana de açúcar, Co 419, e o seu crescimento em função da idade. Anais da ESALQ, 16: 167-190.

DAVIES, E. B., 1956 - Factors affecting molybdenum availability in soils: Soil Science, 81: 209-221.

EVANS, H. 1955 - Studies in the Mineral Nutrition of Sugar Cane as Revealed by Foliar Analysis: Tropical Agriculture 32: 295-322.

EVANS, H. J., 1956 - Role of molybdenum in plant nutrition. Soil Science 81: 199-208.

EVANS, H., 1959 - Elements other than nitrogen potassium and phosphorus in the mineral nutrition of sugar cane. Proceedings of the $10^{\mathrm{ht}}$ Congress of the International Society of Sugar cane Technologists 407-508 (1959).

GLÓRIA, N. A., 1963 - Sôbre uma modificação na determinação de molibdênio em plantas. No prelo dos Anais da ESALQ, vol. 20 (1963).

HEWITT, E. J., 1956 - Symptoms of molybdenum deficiency in plants. Soil Science 81: 159:171.

JOHNSON, C. M. \& T. H. ARKLEY, 1954 - Determination of Molybdenum in Plant Tissue. Analytical Chemistry, 26: 372-573.

PELLEGRINO, D., R. A. CATANI, H. BERGAMIN FILHO, \& N. A.

DA GLóRIA, 1962 - A absorção do zinco pela cana de açúcar, Co 419, em função da idade. No prelo dos Anais da ESALQ, vol. 19 (1962).

PELLEGRINO, D., R. A. CATANI, H. BERGAMIN FILHO \& N. A.

DA GLÓRIA, 1962 - A absorção do manganês pela cana de açúcar, Co 419, em função da idade. No prelo dos Anais da ESALQ, vol. 19 (1962).

SCOTT, W. W., 1939 -. Standard Methods of Chemical Analysis. D. Van Nostrand Co. Inc. Princeton, New Jersey, vol .1-5th ed. pp. 589-590.

SCOTT, P. R. \& C. N. JOHNSON, $1965-$ Molybdenum deficiency in horticultural and field crops. Soil science 81: 183-190. 